\title{
Comparing Two Methods for Measuring Soil Bulk Density and Moisture Content
}

\author{
Jalal D. Jabro, William B. Stevens, William M. Iversen \\ USDA, Agricultural Research Service, Northern Plains Agricultural Research Laboratory, Sidney, Montana, USA \\ Email: jay.jabro@usda.gov
}

How to cite this paper: Jabro, J.D., Stevens, W.B. and Iversen, W.M. (2020) Comparing Two Methods for Measuring Soil Bulk Density and Moisture Content. Open Journal of Soil Science, 10, 233-243. https://doi.org/10.4236/ojss.2020.106012

Received: March 19, 2020

Accepted: June 9, 2020

Published: June 12, 2020

Copyright (c) 2020 by author(s) and Scientific Research Publishing Inc. This work is licensed under the Creative Commons Attribution International License (CC BY 4.0).

http://creativecommons.org/licenses/by/4.0/

(c) (i) Open Access

\begin{abstract}
Soil bulk density and moisture content are dynamic properties that vary with changes in soil and field conditions and have many agricultural, hydrological and environmental implications. The main objective of this study was to compare between a soil core sampling method (core) and the CPN MC-3 Elite $^{\mathrm{Tm}}$ nuclear gauge method (radiation) for measuring bulk density $\left(\rho_{B}\right)$ and volumetric moisture content $\left(\theta_{v}\right)$ in a clay loam soil. Soil $\rho_{B}$ and $\theta_{V}$ measurements were determined using the core and radiation methods at $0-10$ and 10 - $20 \mathrm{~cm}$ soil depths. The mean values of soil $\rho_{B}$ obtained using the core method $\left(1.454,1.492 \mathrm{~g} \cdot \mathrm{cm}^{-3}\right)$ were greater than those obtained using the radiation method $\left(1.343,1.476 \mathrm{~g} \cdot \mathrm{cm}^{-3}\right)$ at the $0-10$ and $10-20 \mathrm{~cm}$ depths, respectively. Mean $\rho_{B}$ and $\theta_{V}$ values averaged across both depths (referred to as the 0 - $20 \mathrm{~cm}$ depth) measured by the core method were $4.47 \%$ and $22.74 \%$ greater, respectively, than those obtained by the radiation method. The coefficients of variation $(\mathrm{CV})$ of soil $\rho_{B}$ values measured by the core method were lower than the $\mathrm{CV}$ values of those measured by the radiation method at both depths; however, the CV's of $\rho_{B}$ values for both methods were larger at the $0-10 \mathrm{~cm}$ depth than those measured at the $10-20 \mathrm{~cm}$ depth. Similarly, the CV values of soil $\theta_{v}$ values measured by the core method were lower than the CV values of those measured by the radiation method at both depths. There were significant differences between two methods in terms of $\rho_{B}$ and $\theta_{v}$, with the core method generating greater values than the radiation method at the $0-20 \mathrm{~cm}$ depth. These discrepancies between the two methods could have resulted from soil compaction and soil disturbance caused by the core and radiation techniques, respectively, as well as by other sources of error. Nevertheless, the core sampling method is considered the most common one for measuring $\rho_{B}$ for many agricultural, hydrological and environmental studies in most soils.
\end{abstract}

\section{Keywords}

Soil, Bulk Density, Moisture Content, Core Method, Radiation Method 


\section{Introduction}

Quantifying soil bulk density, defined as the ratio of oven-dried soil mass per unit volume, is an important for evaluating land management and farming practice effects on soil physical and hydraulic properties [1] [2]. Soil bulk density is also used to convert gravimetric measurements of soil water contents to a volumetric basis and to calculate total soil porosity. It can be used as an indicator of soil compaction, which in turn affects soil porosity, water movement, rooting depth, and water holding capacity. It is also influenced by soil texture, total porosity, amount of organic matter, moisture content and land management practices [1]. For undisturbed and uncompacted soils, bulk density values usually range from $1.26-1.44 \mathrm{~g} \cdot \mathrm{cm}^{-3}$ for clayey soils to $1.44-1.63 \mathrm{~g} \cdot \mathrm{cm}^{-3}$ for sandy soils [3]. It is lower in soils with high amounts of organic matter such as rangeland, pastured soils, and forest soils.

Numerous field methods have been developed for measuring soil bulk density. These include the core or cylinder method, excavation method, clod method, and radiation method [1] [4]. These methods seem to be labor intensive and time-consuming. Some of these methods have been compared with each other and the results of these comparisons showed high inconsistency under field conditions. However, the core method appears to be the most common [5] [6] [7].

Al-Shammary et al. [7] provided a thorough review of different techniques for measuring soil bulk density and listed their advantages and disadvantages, accuracy, and sources of error. They concluded that the core method for measuring soil bulk density is more susceptible to greater errors than other techniques, while the radiation method has better accuracy. They also added that the core method is labor intensive, costly, and difficult to use when sampling at various and increasing soil depths.

Further, Erbach [8] concluded that methods for measuring soil bulk density and moisture content (e.g., core, gamma attenuation, excavation) are difficult, time consuming, inaccurate and prone to many sources of error. He also noted that few studies have evaluated and compared different methods in terms of performance, accuracy, time, and cost.

Wood et al. [9] compared three methods for measuring bulk density in a forest soil and found good agreement between the traditional hand-held soil sampler, Shelby tube, and nuclear gauge methods. They further concluded that no single method for measuring soil bulk density can be absolute and the nuclear gauge was the most economical, and least time-consuming compared to the other two methods used in their study.

Conversely, Page-Dumroese et al. [10] compared five methods for determining bulk density in rocky field soils. They concluded that all methods were easy to use, the core method gave the highest estimate of soil bulk densities, and each method provided variable results.

To our knowledge, no prior studies have examined the relationship between the soil core sampling method and the CPN MC-3 elite method for measuring 
bulk density and moisture content using a large number of measurements. In view of the inconsistency in soil bulk density results produced by different techniques, the objective of this study was to compare the soil core sampling method (core) and the CPN MC-3 elite nuclear gauge method (radiation) for measuring bulk density $\left(\rho_{B}\right)$ and volumetric moisture content $\left(\theta_{v}\right)$ in a clay loam soil.

\section{Materials and Methods}

\subsection{Site and Soil Description}

A field study was initiated at the Montana State University Eastern Agricultural Research Center (EARC) located near Sidney, MT, USA (latitude 47.7255 N, longitude $104.1514 \mathrm{~W}$, elevation $650 \mathrm{~m}$ ).

The study area was planted to sugar beet (Beta vulgaris L.) in 2008 and barley (Hordeum vulgare L.) in 2007. The last tillage was performed in the fall of 2008 following the sugar beet harvest. On 24 October 2008 the area was disked (JD640, John Deere, Moline IL), roller harrowed on 31 October 2008 and leveled [11].

The soil series at the site is Savage clay loam (fine, smectitic, frigid Vertic Argiustolls, US Taxonomy) [11] with $20 \%-21 \%$ sand, $41 \%-43 \%$ silt, and $37 \%$ $38 \%$ clay, and $1.6 \%$ organic matter at the $0-30 \mathrm{~cm}$ depth. The site is nearly level ( $0-2 \%$ slope) and consists of deep, well-drained soil formed in alluvium parent material [11].

\subsection{The CPN MC-3 Elite ${ }^{\mathrm{TM}}$ Nuclear Gauge Description}

The CPN MC-3 Elite ${ }^{\mathrm{Tx}}$ has two radioactive sources. This enables it to determine both the moisture and the density. It uses a cesium-137 $\left({ }^{137} \mathrm{Cs}\right)$ source that emits gamma rays for density measurements and an americium 241/beryllium $\left({ }^{241} \mathrm{Am}-\mathrm{Be}\right)$ source that emits neutrons for measurements of moisture content. The probe has an integrated depth rod, which allows the probe to be lowered in increments of 25 or $50 \mathrm{~mm}$ to a maximum depth of $300 \mathrm{~mm}$. More details about the CPN MC-3 Elite Nuclear Gauge are provided in the operating manual (http://www.instrotek.com/).

\subsection{Soil Bulk Density $\left(\rho_{B}\right)$ and Moisture Content $\left(\theta_{v}\right)$ Measurements}

In this manuscript, we refer to the soil core method as "core" and to the CPN MC-3 Elite ${ }^{\mathrm{Tm}}$ nuclear gauge method as "radiation" for measuring soil bulk density and moisture content.

\subsubsection{Core Method}

Soil core sampling is a direct method and the most common method for measuring $\rho_{B}$ and $\theta_{v}$ in agricultural soils. Soil $\rho_{B}$ values were determined using the core method [1]. Undisturbed soil core samples were collected using a stainless steel coring ring ( $50 \mathrm{~mm}$ internal diameter and $50 \mathrm{~mm}$ length) from each plot at $0-10$ and $10-20 \mathrm{~cm}$ depths. Soil cores were oven-dried at $105^{\circ} \mathrm{C}$ for 24 hours. Bulk density was calculated by dividing the mass of oven dried soil by the core 
volume and gravimetric moisture content was calculated as the mass of water in the soil sample per mass of the oven dried soil $\left(\mathrm{g} \cdot \mathrm{g}^{-1}\right)$. Soil $\theta_{V}\left(\mathrm{~cm}^{3} \cdot \mathrm{cm}^{-3}\right)$ was obtained by multiplying gravimetric moisture content, $\theta_{m}\left(\mathrm{~g} \cdot \mathrm{g}^{-1}\right)$ by soil $\rho_{B}\left(\mathrm{~g} \cdot \mathrm{cm}^{-3}\right)$.

Sixteen soil cores were collected from both compacted and uncompacted plots at each depth $(0-10 \mathrm{~cm}$ and $10-20 \mathrm{~cm})$ for each sampling date. Sampling dates were 14 June 2010, 27 Sept 2010, 8 June 2011, and 2 Sept 2011 [11].

\subsubsection{Radiation Method}

The radiation method is considered an indirect and non-destructive method for estimating soil bulk density. A soil surface area was prepared and smoothed using the edge of the scraper plate provided with the gauge to remove raised areas and obstacles and to fill voids. Small voids were filled with surrounding soil materials. A guide plate was placed on the ground and a drill rod was driven to desired soil depth using a hammer. The rod was pulled out of the ground and the plate was removed. The MC-3 unit was placed over the drilled hole with the source rod extended. Good care was taken to prevent damage to the drilled hole as the unit was lowered to the ground. The source was retracted and the measuring period started. The measurements continued until the desired depth was reached (http://www.instrotek.com/). Sixty-four measurements were made at each depth $(0-10 \mathrm{~cm}$ and $10-20 \mathrm{~cm})$ in both compacted and uncompacted plots adjacent to soil core locations.

\subsection{Statistical Analysis}

Several statistical methods were explored to compare soil $\rho_{B}$ and $\theta_{V}$ measurements from the core and radiation methods. Descriptive statistics were presented for $0-10$ and $10-20 \mathrm{~cm}$ depths, and two depths combined $(0-20 \mathrm{~cm})$. However, data from $0-20 \mathrm{~cm}$ depth were used for other statistical analyses.

A paired t-test using SAS software [12] was used to test the null hypothesis that the mean difference $(M d)$ is zero between pair measurements obtained by these two methods. The $M d$ (Equation (1)) is a measure of the average difference between measurements of core and radiation methods:

$$
M d=\frac{\sum_{i=1}^{n}\left(\text { core }_{\mathrm{i}}-\text { radiation }_{\mathrm{i}}\right)}{n}
$$

where core is the value of soil $\rho_{B}$ or $\theta_{V}$ measured by the core method, radiation is the corresponding value measured by the radiation method, and $n$ is the number of measurements.

The root mean square error, RMSE (Equation (2)), was employed to determine the total difference between the measurements of two methods. A smaller $R M S E$ indicates a good coincidence agreement between the measurements of two methods.

$$
R M S E=\left[\frac{1}{n} \sum_{i=1}^{n}\left(\text { core }_{i}-\text { radiation }_{i}\right)^{2}\right]^{0.5}
$$


where, variables are defined as for Equation (1).

Linear equations were generated from the regression of core and radiation measurements. The coefficient of determination $\left(R^{2}\right)$ that measures how close the data points are to the fitted regression line, and a test of the null hypothesis of an intercept of zero and a slope equal to one were used as a measure of a 1:1 relationship and the degree of association between measurements of two methods [13].

Furthermore, differences between a pair of measurements (core - radiation) were also plotted against their mean values ((core + radiation)/2) to determine if the measurements from the two methods were comparable. If the measurements from both methods are similar, differences should be small, centered near zero, and show no systematic variation in the differences against the means of the measurement pairs [13] [14].

\section{Results and Discussion}

The arithmetic mean, coefficient of variation $(\mathrm{CV})$, minimum and maximum values of soil $\rho_{B}$ and $\theta_{V}$ measurements from the core and radiation methods determined at $0-10,10-20 \mathrm{~cm}$ depths and the two depths combined $(0-20 \mathrm{~cm})$ are given in Table 1.

The mean values of soil $\rho_{B}$ obtained from the core method $(1.454,1.492$ $\left.\mathrm{g} \cdot \mathrm{cm}^{-3}\right)$ were greater than those obtained from the radiation method (1.343, $1.476 \mathrm{~g} \cdot \mathrm{cm}^{-3}$ ) at $0-10$ and $10-20 \mathrm{~cm}$ depths, respectively (Table 1 ). Soil $\rho_{B}$

Table 1. Statistical analysis for soil bulk density and volumetric moisture content measured by the core and radiation methods at the $0-10,10-20$, and $0-20 \mathrm{~cm}$ depths in a clay loam soil.

\begin{tabular}{|c|c|c|c|c|c|c|c|}
\hline \multirow{3}{*}{ Soil property* } & \multirow{3}{*}{ Statistics } & \multicolumn{6}{|c|}{ Depth, cm } \\
\hline & & \multicolumn{2}{|c|}{$0-10$} & \multicolumn{2}{|c|}{$10-20$} & \multicolumn{2}{|c|}{$0-20$} \\
\hline & & core & radiation & core & radiation & core & radiation \\
\hline \multicolumn{8}{|l|}{ Bulk density, $\mathrm{g} \cdot \mathrm{cm}^{-3}$} \\
\hline & Mean & 1.454 & 1.343 & 1.492 & 1.476 & 1.473 & 1.410 \\
\hline & $\mathrm{CV}, \%^{\#}$ & 5.759 & 7.594 & 4.693 & 6.421 & 5.337 & 8.422 \\
\hline & Minimum & 1.256 & 1.187 & 1.300 & 1.302 & 1.256 & 1.187 \\
\hline & Maximum & 1.605 & 1.651 & 1.633 & 1.656 & 1.633 & 1.656 \\
\hline \multicolumn{8}{|c|}{$\begin{array}{l}\text { Volumetric moisture } \\
\text { content, } \%\end{array}$} \\
\hline & Mean & 32.74 & 27.47 & 34.40 & 27.85 & 33.57 & 27.35 \\
\hline & $\mathrm{CV}, \%$ & 10.47 & 12.48 & 7.51 & 12.80 & 9.531 & 12.11 \\
\hline & Minimum & 24.78 & 19.30 & 27.60 & 20.65 & 24.78 & 19.30 \\
\hline & Maximum & 38.44 & 35.80 & 39.74 & 36.90 & 39.74 & 36.90 \\
\hline
\end{tabular}

${ }^{*}$ Total number of observation is 60 for each depth (4 missing values at each depth). ${ }^{*} \mathrm{CV}$ is the coefficient of variation. 
measured by the core method was $8.27 \%$ and $1.08 \%$ larger than that obtained by the radiation method at $0-10$ and $10-20 \mathrm{~cm}$, respectively.

The average $\rho_{B}$ across both depths (i.e., $0-20 \mathrm{~cm}$ ) was 1.473 and $1.410 \mathrm{~g} \cdot \mathrm{cm}^{-3}$ for the core and radiation methods, respectively. Averaged across $0-20 \mathrm{~cm}$, soil $\rho_{B}$ values were greater with the core method than with the radiation method by approximately $4.47 \%$ (Table 1 ).

The CV values of soil $\rho_{B}$ measured by the core method were lower than the $\mathrm{CV}$ values of those measured by the radiation method at both depths (Table 1 ). However, the CV's of $\rho_{B}$ for both methods were larger at the $0-10 \mathrm{~cm}$ depth than those at the $10-20 \mathrm{~cm}$ depth, which indicated more variation in $\rho_{B}$ measurements at $0-10 \mathrm{~cm}$ depth (surface layer) than at $10-20 \mathrm{~cm}$ depth (subsurface layer).

Generally, soil $\theta_{V}$ measurements at $0-10 \mathrm{~cm}$ and $10-20 \mathrm{~cm}$ produced by the core and radiation methods followed the same trend as did soil $\rho_{B}$ measurements (Table 1). Soil $\theta_{V}$ measured by the core method was greater than that measured by the radiation method at both depths. When averaged over two depths $(0-20$ $\mathrm{cm}$ ), soil $\theta_{V}$ was $22.74 \%$ greater with core method than with the radiation method (Table 1).

Similarly, the CV values of soil $\theta_{V}$ values measured by the core method were lower than the $\mathrm{CV}$ values of those measured by the radiation method at both depths (Table 1).

In this manuscript, the $0-10 \mathrm{~cm}$ and $10-20 \mathrm{~cm}$ depths were combined $(0-20$ $\mathrm{cm})$ to assess relationships between core and radiation methods in terms of soil $\rho_{B}$ and $\theta_{V}$ measurements. The mean difference $(M d)$, the root mean squared error $(R M S E)$, the coefficient of determination $\left(\mathrm{R}^{2}\right)$, and linear regression parameters (intercept, a; slope, b) for soil $\rho_{B}$ and $\theta_{V}$ across the $0-20 \mathrm{~cm}$ depth are listed in Table 2.

The $M d$ and $R M S E$ were used to determine degrees of association and coincidence, respectively, between core and radiation methods for soil $\rho_{B}$ and $\theta_{r}$. The paired t-test was used to compare soil $\rho_{B}$ and $\theta_{V}$ values produced by the core and radiation methods. The $M d$ values for soil $\rho_{B}$ and $\theta_{V}$ were $0.0638 \mathrm{~g} \cdot \mathrm{cm}^{-3}(\mathrm{n}=120$, $\mathrm{t}=8.11, \mathrm{P}<0.0001)$ and $6.190 \%(\mathrm{n}=120, \mathrm{t}=20.11, \mathrm{P}<0.0001)$, respectively,

Table 2. Statistical parameters for soil bulk density and volumetric moisture content for two depths combined $(0-20 \mathrm{~cm})$.

\begin{tabular}{ccc}
\hline Statistical parameter & Soil bulk density $\left(\mathrm{g} \cdot \mathrm{cm}^{-3}\right)$ & Volumetric moisture content (\%) \\
\hline$M d^{*}$ & 0.0638 & 6.190 \\
$R M S E$ & 0.0573 & 2.814 \\
$\mathrm{a}$ & 0.831 & 20.830 \\
$\mathrm{~b}$ & 0.456 & 0.403 \\
$\mathrm{R}^{2}$ & 0.474 & 0.201 \\
\hline
\end{tabular}

${ }^{\mathrm{a}} \mathrm{Md}$, is the mean difference; $R M S E$ is the root mean square error, $\mathrm{a}$ is the intercept, $\mathrm{b}$ is the slope, and $\mathrm{R}^{2}$ is coefficient of determination. ${ }^{\star} \mathrm{Md}$ is significantly different from zero at probability level of 0.05 for both parameters. Total number of observations $=120$ (4 missing values at each depth). 
(Table 2). The $M d$ values were large, positive, and significantly different from zero for both soil properties. The positive $M d$ values indicated that the core method produced greater values of soil $\rho_{B}$ and $\theta_{V}$ than did the radiation method (Table 2).

The $R M S E$ values for $\rho_{B}$ and $\theta_{V}$ were $0.0573 \mathrm{~g} \cdot \mathrm{cm}^{-3}$, and $2.814 \%$, respectively (Table 2), which are also somewhat large for both soil physical parameters.

Linear regression equations were determined describing the relationship between the core and radiation methods for soil $\rho_{B}$ and $\theta_{V}$ at $0-20 \mathrm{~cm}$ depth (Figure 1 and Figure 2, respectively). Low degrees of association between two methods for soil $\rho_{B}$ and $\theta_{V}$ were indicated by small coefficients of determination, intercepts

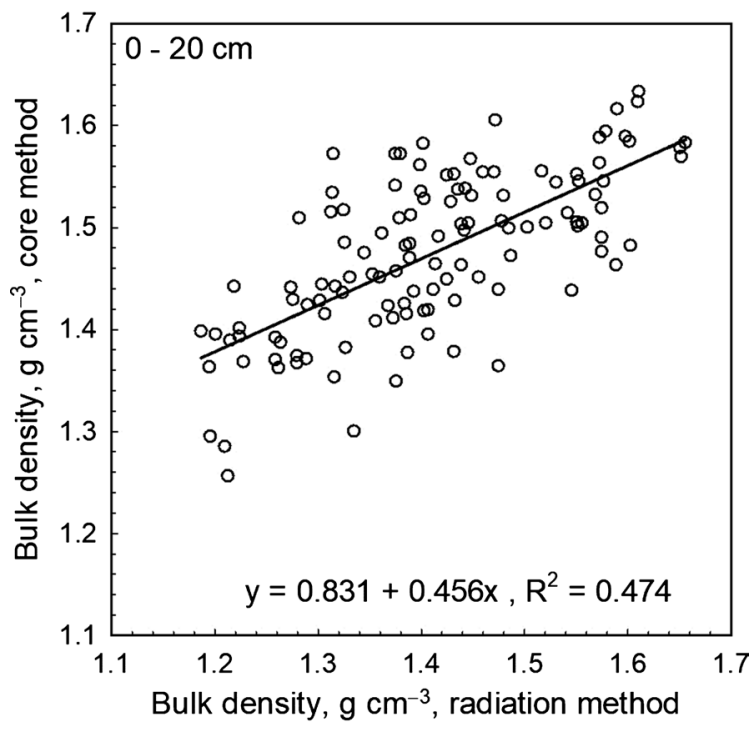

Figure 1. Linear regression between the core and the radiation methods for soil bulk density $\left(\rho_{B}\right)$ for two depths combined $(0-20 \mathrm{~cm})$.

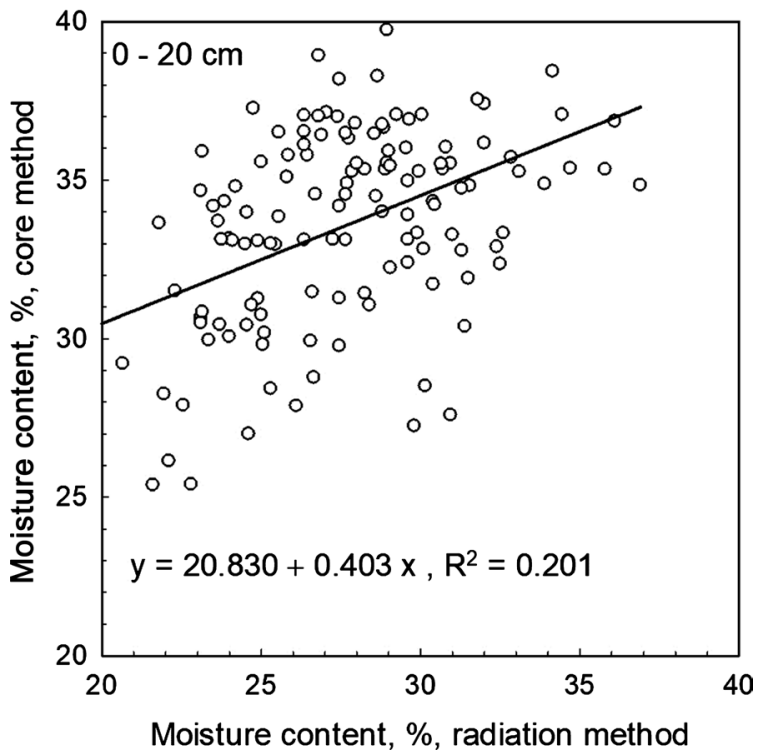

Figure 2. Linear regression between the core and the radiation methods for soil moisture content $\left(\theta_{v}\right)$ for two depths combined $(0-20 \mathrm{~cm})$. 
significantly different from zero, and slopes significantly different from one. A low $\mathrm{R}^{2}$ indicates a poor fit of the linear model describing the relationship between measurements of two methods. These statistical parameters indicated significant differences occurred between two methods for both $\rho_{B}$ and $\theta_{V}$ measurements.

The differences between a pair of measurements (core - radiation) were plotted against their mean values ((core + radiation)/2) for $\rho_{B}$ and $\theta_{V}$ at the $0-20 \mathrm{~cm}$ depth (Figure 3 and Figure 4). These diagrams show that the magnitude of disagreement between pairs of measurements of either $\rho_{B}$ or $\theta_{v}$ from these two methods. Differences were not comparable and scattered far from zero (Figure 3 and Figure 4).

These statistical indicators show that significant differences exist between two methods for both $\rho_{B}$ and $\theta_{v}$ measurements. Discrepancies in $\rho_{B}$ and $\theta_{v}$ measurements between the core and radiation methods could have resulted from differences in soil compaction and soil disturbance caused by the core and radiation techniques, respectively, as well as by other sources of error.

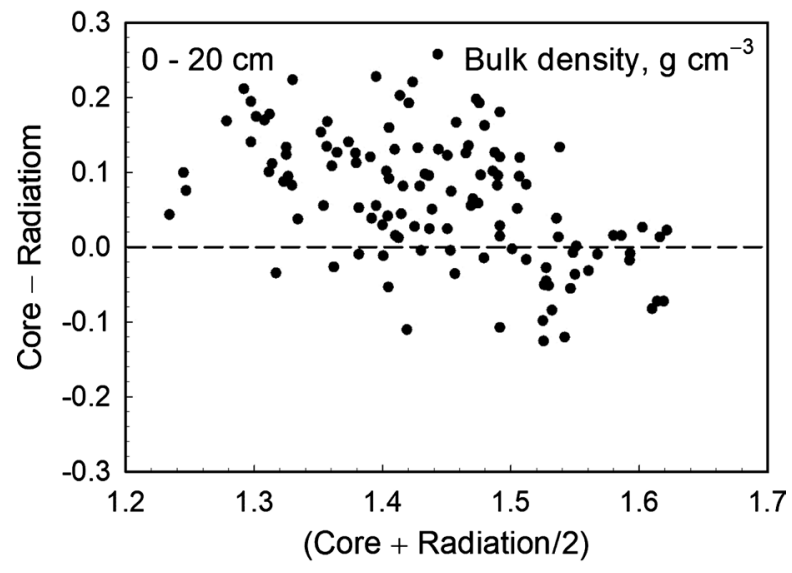

Figure 3. Relationship between the difference and mean of soil bulk density measurements for the core and radiation methods for two depths combined $(0-20 \mathrm{~cm})$.

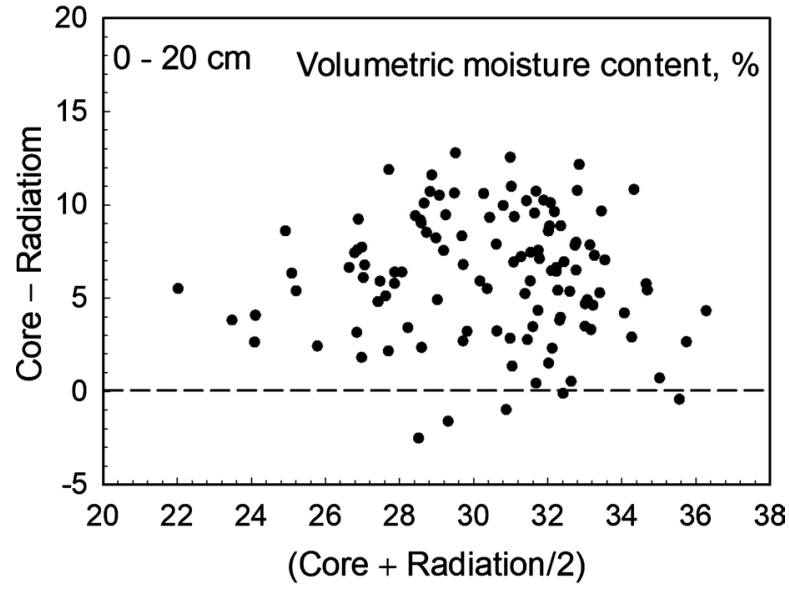

Figure 4. Relationship between the difference and mean of soil moisture content measurements for the core and radiation methods for two depths combined $(0-20 \mathrm{~cm})$. 
These findings were in agreement with those found by [10], who concluded that large differences in soil $\rho_{B}$ existed among five different methods, the core method provided highest estimates of soil $\rho_{B}$ compared to other methods, and $\rho_{B}$ values estimated by the gauge method were more consistence.

Higher $\rho_{B}$ measurements generated by the core sampling method are possibly due to the presence of coarse fragments inside the undisturbed soil core because this method does not account for inter-soil core spaces. Accordingly, corrections must be made for inter-core spaces to obtain accurate measurements of soil $\rho_{B}$, but this process is quite laborious and time consuming [1]. Other reasons for obtaining inaccurate values of $\rho_{B}$ are due to incorrect soil core trimming process. Presence of coarse fragments in the core can make trimming the soil core difficult and may result in an uneven edge leading to inaccurate $\rho_{B}$ measurements. It is also possible that soil in cores may be compacted during the sampling process due to the pounding technique and associated friction between the walls of the steel ring and the soil, thus increasing $\rho_{B}$ values due to an increase in the soil mass. This packing effect would likely be larger when soils are wet, particularly in clay-textured soils. Blake and Hartge [1] have stated that soil $\rho_{B}$ may increase if the sampling device is over-driven into the soil during the hammering process.

Other sources of variation and error in sampling and measurements of soil $\rho_{B}$ and $\theta_{v}$ between core and radiation methods could be associated with the core sampling and weighing processes, calibration, precision and repeatability of the CPN MC-3 Elite ${ }^{\mathrm{TM}}$ gauge, soil surface roughness, presence of voids, hole preparation, variation in gamma attenuation absorption and scattering coefficients due to soil chemical composition, depth of measurement that impacts detection of thermal neutrons counts, field conditions, soil type and conditions, and spatial variability of soils and heterogeneity of soil physical properties such as structure and moisture content (http://www.instrotek.com/).

Recently, Al-Shammary et al. [7] concluded that soil core method for measuring bulk density is prone to greater errors than other techniques while the radiation method has better accuracy than other methods. However, Erbach [8] concluded that all methods for measuring of soil $\rho_{B}$ are difficult, time consuming, inaccurate and prone to many sources of error.

\section{Summary and Conclusions}

Statistical results indicate that there are differences between the core method and the radiation method for both $\rho_{B}$ and $\theta_{V}$ measurements. Averaged across the 0 $20 \mathrm{~cm}$ soil depth, soil $\rho_{B}$ and $\theta_{V}$ values measured by the core method were $4.47 \%$ and $22.74 \%$, respectively, greater than those obtained by the radiation method.

Variation among soil $\rho_{B}$ measurements produced by the core method was less than among measurements produced by the radiation method at the $0-10$ and $10-20 \mathrm{~cm}$ depths. Variation among $\rho_{B}$ measurements was greater with both methods at $0-10 \mathrm{~cm}$ depth than at $10-20 \mathrm{~cm}$ depth.

Different methods for measuring $\rho_{B}$ and $\theta_{v}$ produce different results. These 
methods have advantages and disadvantage for measuring soil $\rho_{B}$ and $\theta_{r}$ which one can consider in selecting an appropriate method for particular goals, situations and conditions.

To date, there is no ideal method for measuring soil $\rho_{B}$ and $\theta_{v}$ though, the core sampling method is the most common one for measuring $\rho_{B}$ for many agricultural, hydrological and environmental investigations in most soils. The accuracy, performance, labor and time requirements and cost of each method must be considered when choosing a method for a particular application.

\section{Acknowledgements}

The authors wish to express their thanks and appreciation to Dale Spracklin at Northern Plain Agricultural Laboratory for measuring soil bulk density and moisture content using the CPN MC-3 elite nuclear gauge and core methods and summarizing the data.

\section{Disclaimer}

Mention of trade names, proprietary products, or specific equipment is intended for reader information only and constitutes neither a guarantee nor warranty by the ARS-USDA, nor does it imply approval of the product named to the exclusion of other products.

\section{Conflicts of Interest}

The authors declare no conflicts of interest regarding the publication of this paper.

\section{References}

[1] Blake, G.R. and Hartge, K.H. (1986) Bulk Density. In: Klute, Ed., Methods of Soil Analysis, Part I Physical and Mineralogical Methods, 2nd Edition, ASA-SSSA, Madison, 363-375. https://doi.org/10.2136/sssabookser5.1.2ed.c13

[2] Jabro, J.D., Toth, J.D. and Jemison, J.M. (1996) Physical and Hydraulic Characteristics of a Hagerstown Silt Loam Soil. Agronomy Series Number 138. College of Agricultural Sciences, Pennsylvania State University, State College.

[3] Campbell, G.S. (1985) Soil Physics with Basic. Transport Models for Soil-Plant Systems. Elsevier Science Publishing Company Inc., New York.

[4] Grossman, R.B. and Reinsch, T.G. (2002) The Solid Phase. In: Jacob, D.H. and Topp, C., Eds., Methods of Soil Analysis, Part 4, Physical Methods, SSSA, Inc., Madison, 201-225.

[5] Throup, H.L., Archer, S.R., Monger, H.C. and Waltman, S. (2012) When Bulk Density Methods Matter: Implications for Estimating Soil Organic Carbon Pools in Rocky Soils. Journal of Arid Environments, 77, 66-71. https://doi.org/10.1016/j.jaridenv.2011.08.020

[6] Casanova, M., Tapia, E., Seguel, O. and Salazar, O. (2016) Direct Measurement and Prediction of Bulk Density on Alluvial Soils of Central Chile. Chilean Journal of Agricultural Research, 76, 105-113. https://doi.org/10.4067/S0718-58392016000100015 
[7] Al-shammary, A.A.G., Kouzani, A.Z., Kaynak, A., Khoo, S.Y., Norton, M. and Gates W. (2018) Soil Bulk Density Estimation Methods: A Review. Pedosphere, 28, 581-596. https://doi.org/10.1016/S1002-0160(18)60034-7

[8] Erbach, E. (1987) Measurement of Soil Bulk Density and Moisture. Transactions of the American Society of Agricultural Engineers, 30, 922-931.

https://doi.org/10.13031/2013.30500

[9] Wood, M.J., Douglas, R.A. and Sands, R. (2004) A Comparison of Three Methods for Measuring the Density of a Forest Soil in New Zealand. International Journal of Forest Engineering, 15, 71-80. https://doi.org/10.1080/14942119.2004.10702491

[10] Page-Dumroese, D.S., Jurgensen, M.F., Brown, R.E. and Mroz, G.D. (1999) Comparison of Methods for Determining Bulk Densities of Rocky Forest Soils. Soil Science Society of America Journal, 63, 379-383. https://doi.org/10.2136/sssaj1999.03615995006300020016x

[11] Jabro, J.D., Iversen, W.M., Evans, R.G., Allen, B.L. and Stevens, W.B. (2014) Repeated Freeze-Thaw Cycles Effects on Soil Compaction in a Clay Loam in Northeastern Montana. Soil Science Society of America Journal, 78, 737-744. https://doi.org/10.2136/sssaj2013.07.0280

[12] SAS Institute (2011) The SAS System for Windows. Version 9.2. SAS Institute, Cary.

[13] Jabro, J.D., Evans, R.G., Stevens, W.B. and Iversen, W.M. (2008) Repeatability of Soil Apparent Electrical Conductivity Measured by a Coulter Sensor. Soil Science, 173, 35-45. https://doi.org/10.1097/ss.0b013e318159a608

[14] Bland, J.M. and Altman, D.G. (1986) Statistical Methods for Assessing Agreement between Two Methods of Clinical Measurements. The Lancet, 1, 307-310. https://doi.org/10.1016/S0140-6736(86)90837-8 